\title{
The use of clip anchoring to ensure safe transgastric puncture during endoscopic ultrasound-guided transmural drainage
}

Endoscopic ultrasound (EUS)-guided transmural drainage (EUS-TD) was recently developed and has proven to be a useful alternative approach for various intra-abdominal conditions [1-3]. In this procedure, an intrathoracic passage should be avoided, because it causes severe complications, such as mediastinitis $[4,5]$. Unfortunately, however, it is difficult to confirm whether a puncture route can be used to pass the thorax using EUS observation alone when approaching from the gastric cardia. Here, we describe the usefulness of clip anchoring at the esophagogastric junction to minimize the risk associated with intrathoracic passage.

A 66-year-old man presented with a high fever after hepatectomy for hepatocellular carcinoma. The contrast-enhanced computed tomography (CT) scan showed fluid collection with gas, indicating an intra-abdominal abscess at the omental bursa (>Fig.1). Although there was no appropriate route for extracorporeal insertion, a curvilinear echoendoscope clearly showed the abscess just beneath the gastric cardia. Using a forward-viewing endoscope, two clips were placed at the esophagogastric junction, avoiding the hiatal hernia ( $\mathbf{F i g . 2 a ) . ~ A ~ 1 9 - g a u g e ~}$ needle was then inserted into the abscess cavity under EUS guidance and fluoroscopic observation at a point distal to the clips (- Fig.2 b). Next, a $6-\mathrm{Fr}$ naso-abscess catheter and 7-Fr doublepigtail stent were inserted ( $\mathbf{F i g . 2 c}$, - Video 1).

The patient's condition quickly improved the next day, and the naso-abscess catheter was removed on the fifth day without any complications.

A CT scan approximately 5 weeks later showed complete resolution of the abscess ( $\mathbf{F i g} \cdot \mathbf{3 a}$ ). The puncture point was endoscopically reconfirmed at a point distal to the clip, which was located at the esophagogastric junction ( $\triangleright$ Fig. 3 b), and the stent was removed.

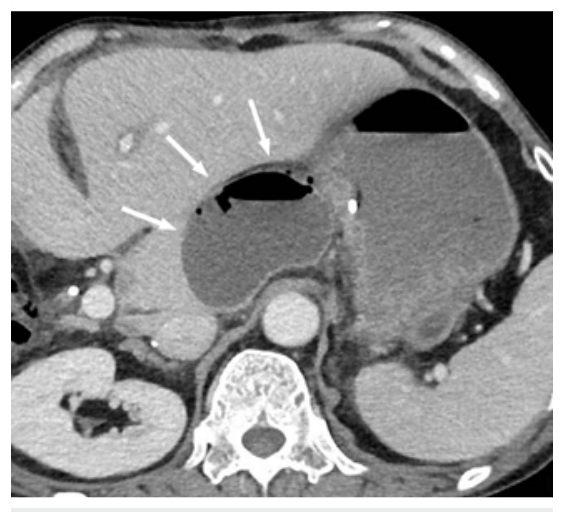

- Fig. 1 Computed tomography scan showing a 7-cm omental bursa abscess adjacent to the stomach (arrows).

The clips do not physically anchor anything in this procedure, but they do anchor a virtual track of insertion and make EUS-TD at the gastric cardia safer.

Endoscopy_UCTN_Code_TTT_1AS_2AC
Competing interests

None

The Authors

Shinichi Morita', Kazuo Hara², Takeshi Suda', Susumu Hijioka ${ }^{2}$, Nozomi Okuno², Masaaki Kobayashi ${ }^{1}$, Shuji Terai ${ }^{3}$

1 Department of Gastroenterology and Hepatology, Uonuma Institute of Hospital, Niigata, Japan

2 Department of Gastroenterology and Endoscopy, Aichi Cancer Center Hospital, Nagoya, Japan

3 Department of Gastroenterology and Hepatology, Niigata University Hospital, Niigata, Japan Community Medicine Niigata University

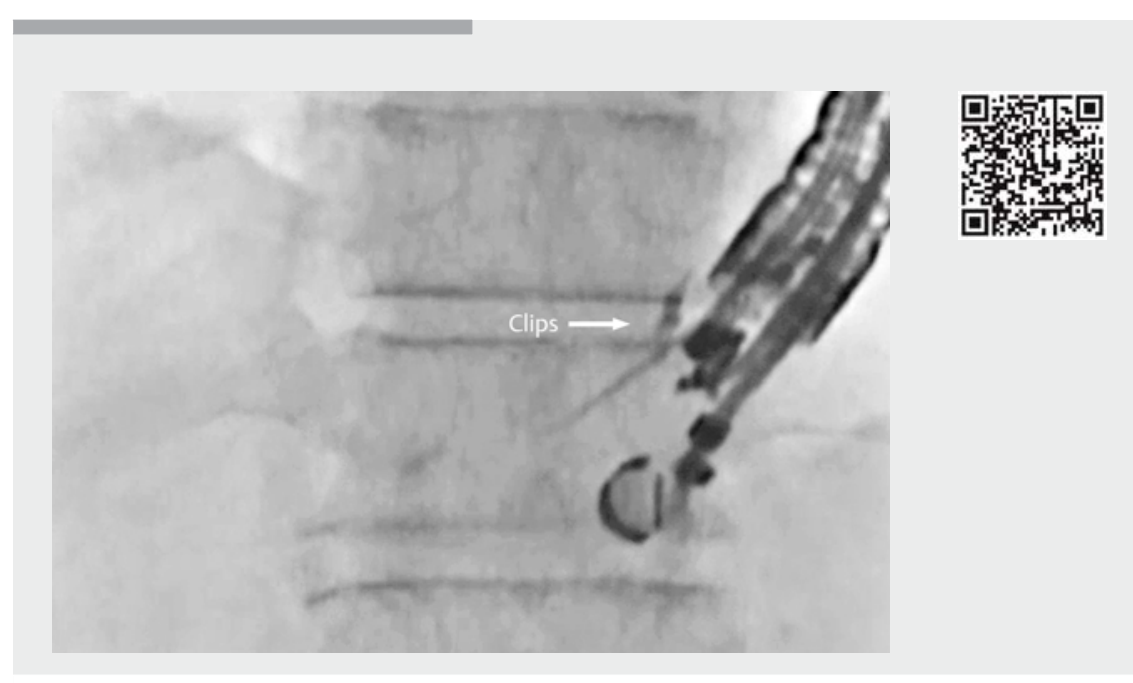

Video 1 The esophagogastric junction was marked with two clips. Endoscopic ultrasound-guided transmural drainage was performed by inserting a needle at a point distal to the clips, and placing a naso-abscess tube and double-pigtail stent into the abscess under fluoroscopic observation. Video still image Fluoroscopic image showing the puncture point positioned distally to the clips (allow). 

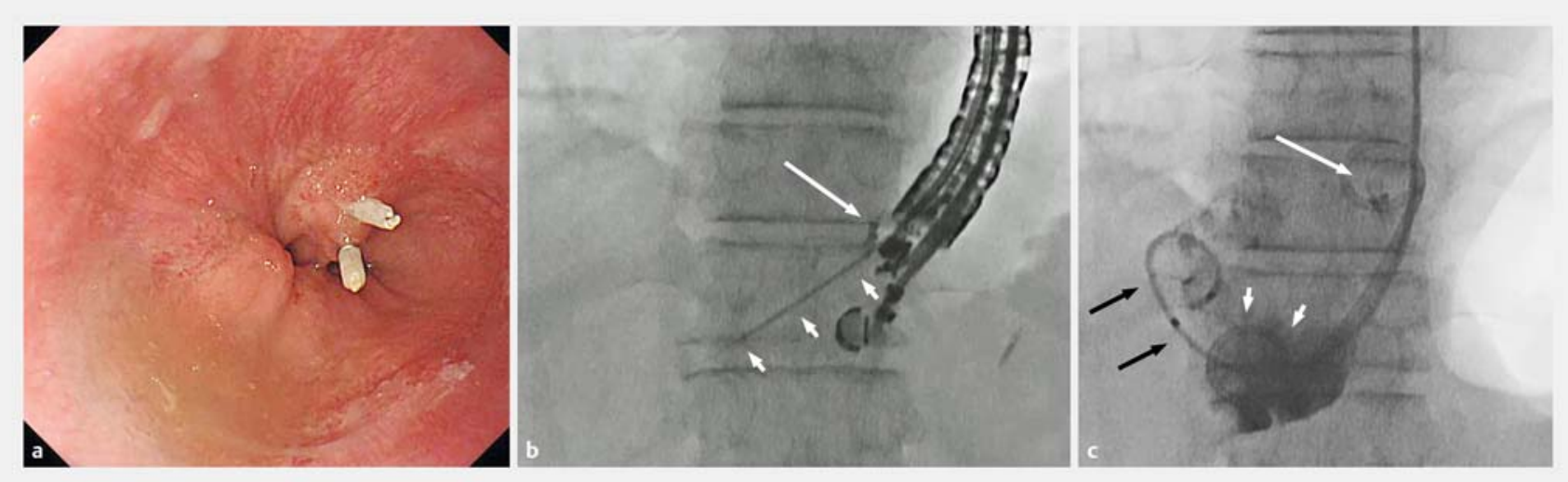

- Fig. 2 Drainage procedure. a Two clips were placed at the esophagogastric junction. b A 19-gauge needle (arrowheads) was inserted into the abscess cavity at a point distal to the clips (arrow). c A 6-Fr naso-abscess catheter (black arrows) and a 7-Fr double-pigtail stent (arrowheads) were then inserted into the abscess cavity through the puncture point distal to the clips (white arrow).
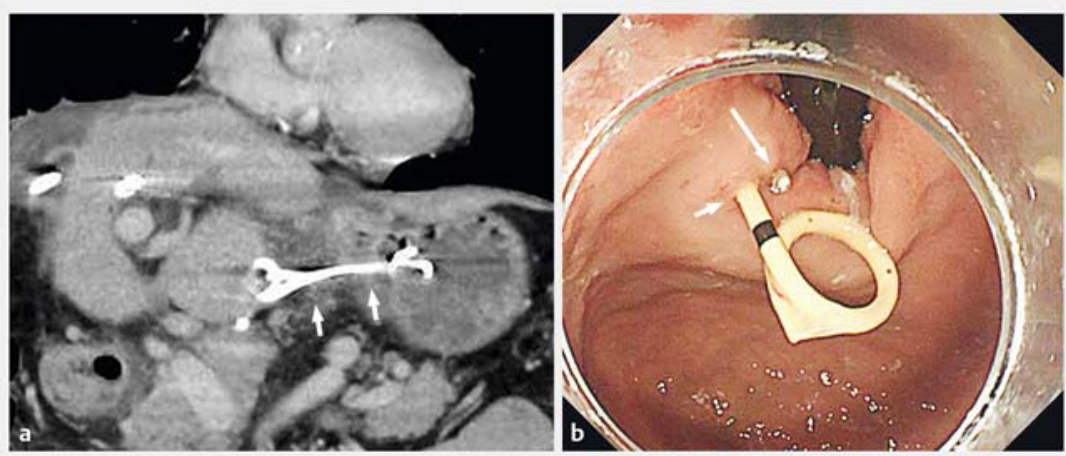

- Fig. 3 Follow-up at 5 weeks. a Computed tomography scan showing the stent (arrowheads) placed through the intra-abdominal route, and the resolved abscess. b Reverse viewing endoscopic image showing the double-pigtail stent (arrowhead) inserted at a point distal to the clip (arrow) at the esophagogastric junction.

\section{Corresponding author}

\section{Shinichi Morita, MD}

Department of Gastroenterology and Hepatology, Uonuma Institute of Community Medicine Niigata University Hospital, 4132 Urasa, Minamiuonuma City, Niigata, 949-7302, Japan

Fax: $+81-25-7772811$

m0riz0u@extra.ocn.ne.jp

\section{Acknowledgment}

We would like to thank Editage (http:// www.editage.com) for English language editing and publication support.

\section{References}

[1] Hara K, Yamao K, Mizuno N et al. Endoscopic ultrasonography-guided biliary drainage: who, when, which, and how? World J Gastroenterol 2016; 22: 1297-1303

[2] Mandai K, Uno K, Yasuda K. Endoscopic ultrasound-guided drainage of postoperative intra-abdominal abscesses. World J Gastroenterol 2015; 21: $3402-3408$

[3] Varayu Prachayakul PA. Endoscopic ultrasound-guided interventions in special situations. World J Gastrointest Endosc 2016; 8: $104-112$

[4] Piraka C, Shah RJ, Fukami N et al. EUS-guided transesophageal, transgastric, and transcolonic drainage of intra-abdominal fluid collections and abscesses. Gastrointest Endosc 2009; 70: 786-792

[5] Bohle W, Zoller WG. Mediastinitis after EUSFNA in a patient with sarcoidosis - case report with endosonographic features and review of the literature. Z Gastroenterol 2014; 52: $1171-1174$

\section{Bibliography}

DOI https://doi.org/10.1055/s-0043-109428

Endoscopy 2017; 49: E186-E187

(c) Georg Thieme Verlag KG

Stuttgart · New York

ISSN 0013-726X

\section{ENDOSCOPY E-VIDEOS}

https://eref.thieme.de/e-videos

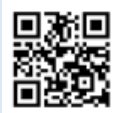

Endoscopy E-Videos is a free access online section, reporting on interesting cases and new

techniques in gastroenterological endoscopy. All papers include a high quality video and all contributions are freely accessible online.

This section has its own submission website at https://mc.manuscriptcentral.com/e-videos 